\title{
Factors Associated in Students' Completion in the Degree Master and Doctor of Philosophy in Educational Planning and Management
}

\author{
Sheryl Ompoc ${ }^{1}$ and Renato L. Base ${ }^{2}$ \\ ${ }^{1}$ Teacher III, Departm ent of Education,Division of Misam is Oriental,Danao National High \\ School, Jasaan Misam is Oriental, Philippines. Email:sheryl.om poc@deped.gov.ph \\ ${ }^{2}$ Faculty, Departm ent of Educational Plann ing and Adm inistration, Un ive rs ity of Science and \\ Technology of Southern Philippines (USTP), Cagayan de Oro City, Philippines. Email: \\ renato.base@ustp.edu.ph.
}

\begin{abstract}
The main objective of the study is to statistically determine whether the characteristics found in the graduate student's profile are associated with their completion of master's and doctorate degrees in Educational Planning and Management. The findings would then be utilized as the basis for further enhancing the profile records of students enrolled in the said program. Likewise through a follow-up study to use such characteristics as predictors of students completing in getting a degree in Educational Planning and Management. Toward this end, the study used an archival research design. The study utilized all available documents relative to the profiles of students as they are archived in the Department of Educational Planning and Management. For reasons of confidentiality and ethical considerations, the study considers only the following characteristics from their profile, namely, gender, age, marital status, years of employment, employment type, and length of completion. The findings have shown that of these characteristics only gender was found to be significantly associated with the completion of master's and doctorate. Based on the findings, it was recommended that the Department should widen the coverage of the characteristics of students that should be included in their profile. As much as possible it should include socio-cultural and economic characteristics and psycho-emotional and intellectual considerations as well. In this way, the next profile of the entrants for the new curriculum, which at present is aptly named educational planning and administration will be more comprehensive and encompassing as compared to the previous one. Therefore, the more characteristics or indicators will be incorporated in the profiling of students, the more it becomes a valuable source of data that will not only be beneficial to the Department but very valuable sources for future study.
\end{abstract}

Keywords: Educational Planning and Management; USTP; graduate school; Factors Associated to Completion of Master and Ph.D. Degree 


\section{INTRODUCTION}

For decades now, the time duration to complete graduate degrees have been the focus of studies (Abedi \& Benkin, 1987; Baird, 1990; Berelson, 1960; Bowen \& Rudenstine, 1992; Filteau, 1992; Harmon, 1978). Nonetheless, Pyke and Sheridan (1993) noted that students' time duration to complete a graduate-level degree cannot be equated. This position seems to withstand the claimed of those studies that even utilized large-scale data sets (National Research Council, 1989). Presently, the trend is to give importance to systematic data collection concerning graduate students in a particular institution. In other words, the present trend is now to give importance to the context and uniqueness of the student's socio-cultural and economic characteristics, which are important when it comes to associating students with the length of time in which they can finish their graduate studies.

From this perspective, this study was conducted to find out the possible variables that are significantly associated with the completion of the master's and doctorate degrees in the context of Educational Planning and Management programs at the University of Science and Technology of Southern Philippines (USTP). Presently, this study is relevant as ever since the inception of the program on Educational Planning and Management, no study had been done yet that deals on the pertinent characteristics found in the profile form that students have to fill up when they are accepted either in the masters or doctorate program. And to ascertain whether these characteristics being elicited from the students have bearing on their completion of their master's or doctorate. In so doing, the findings could provide us with an empirical basis in updating new information in coming up with a new profile form for students in the newly approved curriculum. Thus, this study is a humble contribution to the existing gap in knowledge due to the dearth of literature relative to the factors that are being associated with the completion of a master's degree. At present, this is quite the opposite as compared to the number of literature on the same topic when it comes to factors associated with the completion of a doctorate wherein there was a substantial number of studies. Lastly, the underlying purpose of which is to utilize the findings as inputs in the monitoring of new enrollees for the revised curriculum of the said master's and doctorate programs, which is now aptly named as Educational Planning and Administration. It is, therefore, on this consideration that this study had been conducted.

\section{BRIEF OVERVIEW OF CURRENT LITERATURE}

Studies had reported that the length of time of completing a degree is a function of the time in which the data were collected. The survey conducted by the National Research Council (1989) and Evangelauf (1989) revealed that the normal students that completed a doctoral degree had on average 6.9 years in the graduate school which was a bit higher than the previous years. Corollary to this is the increase in income. Bowen and Rudenstine (1992) had noted that this increase could be artifactual, which is the consequence of grouping students in terms of year of graduation instead of entry to the graduate school. In this study, however, the length of time of completing a master's and doctorate degrees in Educational Planning and Management was reckoned to begin from the student's entry to the program until he/she was conferred the degree.

At the outset, it is imperative to underscore that this brief review of the current literature relative to the length of time to graduate at the master's and doctorate level entails some limitations. We need to emphasize that a considerable number of studies have focused only on doctoral students. This is in contrast to the number of studies that spotlighted the length of time to complete master's degrees (Marr \& McPherson, 1992; Sheinin, 1989; Sheridan, 1992). However, in this study, we strive to shed an insight relative to our master's as well as doctoral students' length of completion of getting the said degrees. And this is somehow a modest contribution to the existing literature in this area particularly within the context of Educational Planning and Management students in the University of Science and Technology of Southern Philippines, Cagayan de Oro Campus. 
In this study, the completion period excludes the time before entry to graduate school but it includes the time between having been officially accepted as a graduate student of the program. And, this covers the time spent on leave, time in which he/she did not enroll for a given semester for whatever reason the students deemed it to be, and until the time the degree has been conferred. Consequently, the study's operational definition of the way of measuring the completion period is quite different could not be likened to what was used by Tuckman, Coyle, and Bae (1989), which they called the registered time to the master/doctorate. Likewise, different from the definition that Yeates (1991) used wherein completion period was defined in terms of the time between receipt of the baccalaureate and receipt of the master/doctorate including the time spent out of the university/college after obtaining the undergraduate degree and before entry into graduate school. In that study by Tuckman, Coyle, and Bae (1989), they found out that, on average, the completion period for a doctorate range from 5.63 years to 7.02 years. The study of Yeates (1991) however it reported that the average completion period for a doctorate is 8.19 years to 9.84 years.

We found out that in the literature the most prevalent variables being studied were between "field of study" and "time to completion", and how these two were associated with each other. In a study conducted by Duggan (1989), on average, the length of time to complete a doctorate was 6.9 years though the study had taken notice that variability exists across disciplines. This variability showed that those pursuing a degree in languages and literary studies took 8.9 years, those in the arts 8.6 years, and those in the social sciences 8.4 years. And, while those in the engineering, physical sciences, and biological sciences, on average, took 5.5, 6 years, and 6.2 years respectively to complete their degree requirements.

Yeates (1991), on the other hand, reported that the fastest time to completion was 4.5 years, and it occurred with students pursuing a doctoral degree in the field of science while those in the social sciences and the humanities achieved a median completion time of 5.6 years. These findings appeared validated by the result of a survey conducted by Fletcher and Stren (1992) in which they reported that, on average, students in the humanities, social sciences, education, and law take significantly longer to complete their doctoral degree compared to students in the engineering, physical and biological sciences. And, between these two fields could be found the intermediate professional programs, e.g. Doctor in Business Administration, Doctor in Public Administration, and among others.

Another variable being studied by investigators is the association between doctoral students' availing of financial support and time to complete their degrees. In a study conducted by Abedi and Benkin (1987), on average, students who pursued their doctoral studies and relied only on their earnings took two years longer to finish their degree compared to those students with external financial support in their studies. Furthermore, doctoral students awarded with grants and fellowships took even longer to complete their doctorate degrees compared with those supported through research or teaching assistantships. According to Abedi and Benkin (1987), the reason for this could be attributed to the influence of getting funding via grants and fellowships that resulted in an increased amount of time spent on non-degree-related activities. As a result, pursuing such nondegree-related activities inevitably extend the time of completion. This observation appeared to find support from Bowen and Rudenstine (1992). They declared that students who relied on their financial resources have longer times to completion than doctoral students that receive financial support. However, they emphasized that the source or form of funding was much less relevant. This declaration of Bowen and Rubenstine (1992) did not converge with the findings of Tuckman, Coyle, and Bae (1990) in which they averred that fellowship funding contributed to shorter completion times whereas personal financing, research, or teaching assistantships increased time to completion. It must also be noted that the findings of Bowen and Rubenstine (1992) relative to fellowships vis-à-vis teaching assistantships was consistent with that of Tuckman et al. (1990). However, Fletcher and Stren (1992), asserted that financial considerations weigh in heavily in the speedy completion of doctoral degrees especially those in the humanities and social sciences. 
Another popular variable of the study is that of Gender focusing in particular on differences in male and female time about their completion. Those researchers who research such differences have found out that female $\mathrm{Ph} . \mathrm{D}$. students take longer to finish their degree than males (Tuckman et al., 1990). However, Bowen and Rudenstine (1992) and MacMillan (1989) have posited that gender differences are not consistent in all fields and disciplines. They attributed this to the fact that there are disciplines in which the sexes are particularly concentrated. Likewise, there is the type of financial support that is gender-based (Berg \& Ferber, 1983). Notwithstanding all these considerations, Sheinin (1989) noted that except for education and the life sciences, the completion for doctoral degrees of females was generally longer compared to that of males, that is, 6.1 years for females and 5.6 years for males. Yeats (1919), on the other hand, in a cohort study being conducted reported that in the ' 80 s male completion is faster than that of females, that is, 4.7 years for males and 5.3 years for females.

At this juncture, there is a need to underscore that there is a dearth of published studies when it comes to the length of completion of students at the master's level. According to Marr \& McPherson (1992), they reported that on average the length was 35 months to the master's degree. This was in a study conducted on a large cohort of graduate students. In this study, he found differences in length of time to degree by area of study, with students in the humanities and fine arts requiring 41 months on average. This was then followed by students in the physical and engineering sciences for 36 months on average. Students in the social sciences 35 months on average, and students in the life sciences 33 months on average.

Furthermore, Marr and McPherson (1992) provided descriptive information on 29 master's programs. They found that the median time to completion was 28 months, and it range from 24 to 40 months. However, a longer time to degree completion was observed in the physical and biological sciences. In the same vein, longer average completion was also reported for programs with thesis requirements as opposed to major research projects only, and those in combination with coursework or even coursework alone.

On the other hand, Sheinin (1989) had reported that the average time to completion of master's degrees was, on average, 2.1 years, with women completing slightly more quickly on average, 2.0 years than men, 2.4 years. Concerning completion time in doctoral programs, some area of study differences were observed, with longer times to completion in education, on average, 2.9 years, and the life sciences, 2.4 years, and shorter times in the humanities 1.8 years, on average, and the social science at 1.9 years.

\section{STATEMENT OF THE PROBLEM}

The main objective of this study is to come up with evidence whether the characteristic found in the graduate students' profiles are associated with their completion of master's and doctorate degrees in the Educational Planning and Management program. There is a need to note that at present the old profile contained only the following information: gender, age, marital status, years of employment, employment type. The evidence would then be utilized in the possible enhancement of the information in the graduate student's profile. The information contain in this profile is crucial for future study utilization as well as use the said information in the assessment of the student's potential completion of the program, i.e. master's or doctorate, in which they enrolled. There is, therefore, a need to update or even enhance the information in this profile form. Hence, this objective.

Given this, the following questions are being posited.

1. What is the characteristic of students that have already completed their master's and doctorate, in terms of the following characteristics?
a. Sex
b. Age
c. Marital Status 
d. Years in employment

e. Employment Type

f. Length of completion

2. What is the average length of completion of master's and doctorate students?

3. Is sex significantly associated with getting a master's and doctorate?

4. Is age significantly associated with the length of completion in getting a master's and doctorate?

5. Is marital status significantly associated with getting a master's and doctorate?

6. Is years in employment significantly associated with length of completion in getting a master's and doctorate?

7. Is the employment sector significantly associated with getting a master's and doctorate?

8. Is employment type significantly associated with length of completion in getting a master's and doctorate?

\section{DEFINITION OF TERMS}

The following terms are defined operationally in this study.

Age - This refers to the number of years reckoned since his/her birth until the time he/she graduated in one of the programs in Educational Planning and Management, i.e. master or doctor of philosophy degree.

Employment Type - This refers to the sector of employment whether privately employed or publicly (in the government) employed the students that finished an Educational Planning and Management Degree program are working in the last 10 years while still being a student of the said program.

Length of Completion - This refers to the number of years beginning from the time the student was first accepted and officially enrolled in the program until the time he/she completed the program. These numbers of years include but are not limited to all the years in between the time he/she was first officially accepted as a student of the program until the time he/she completed the degree in master or doctor of philosophy.

Marital Status - This refers to the three types of marital status, i.e. single, married, and complicated, the students had three years before he/they completed the Educational Planning and Management degree program in the master or doctor of philosophy degree. A Complicated marital status refers to any other type of marital status besides that of being single or married.

Gender - This refers to the biological sexes of the students that completed the degree.

Years in employment - This refers to the cumulative number of years that the student had been employed in the private or public sector.

\section{METHODOLOGY}

\section{Locale of the Study}

The study was conducted on the campus of the University of Science and Technology of Southern Philippines (USTP) Cagayan de Oro City Campus, which hosted the two graduate programs in master's and doctor of philosophy in Educational Planning and Management (EPM). After the said program's curriculum had been enhanced to make it more responsive to the demand of the time, hence, with due consultation to stakeholders, the program was renamed into Educational Planning and Administration.

Research Design

The study uses an archival research design. As such, the study utilized data that was collected and had been archived in the Department of Educational Planning and Administration. These data can be found in the profile that students in the program have to fill up for purposes of record keeping. The pertinent characteristics in 
their profile, which this study utilized, were as follows: age, employment type, length of completion, marital status, gender, and years in employment. Other relevant information could not be included for the reason of confidentiality. All available documents as kept by the Department relative to the student's characteristics as reflected in their profile were utilized in this study.

Sampling Design

At this point, it must be emphasized that the study did not use any form of sampling methodology. As expected, the sampling is supposed to be done on documents about the profiles of those that graduated from the program. On this point, we need to underscore that all available documents relative to the profiles of those that completed the master's or doctor of philosophy degree were included in this study. All these documents became sources of data about the aforementioned characteristics. Hence, no sampling of these documents occurred but rather total enumeration was done.

Instrument

Given that, the study used an archival research design, the instrument in data gathering were those Profile Forms that students in the program, master or doctorate, must fill up. The Profile Form serves as the instrument of this study. We need to note that the Department keeps the profiles of its students by letting them fill up the profile Form for record purposes, and for future utilization, which in this case was being utilized in this study. Data Analysis

At this juncture, we need to underscore that the variables sex, marital status, and employment type were measured at the nominal level. Hence, we analyze these data using frequency count and percentage.

The variables age, length of time of completing the degree, and years in employment were measured at the interval/ratio level. Hence, we analyze these data using the mean coupled with the standard deviation.

To provide a clear descriptive picture of the characteristics of the students, we, therefore, cross-tabulated gender with the rest of the characteristics under consideration in this study.

In analyzing Questions 1 and 2 in the Statement of the Problem, descriptive statistics were applied. For Questions 3, 5, 7, and 8, the Chi-Square test of independence was used with effect sizes determined. Furthermore, for Questions 4 and 6, the Pearson Product Moment Correlation was used.

\section{RESULTS AND DISCUSSION}

\section{Characteristics of EPM Graduates}

A. Master's Student's Respondents Profile with Number of Years of Completion

As found out in this study, the master's and doctorate graduate respondents reflected the following characteristics. As shown in Tables 1 and 2 below, in which these characteristics are depicted in terms of gender, employment sectors, marital status, age, years of employment, and length of completion time. We need to note though that presenting the characteristics of these respondents was cross-tabulated with the other characteristics to provide a clear picture of the respondent's overall profile.

As reflected in Table 1, 25.7\% of respondents with Master's Degree in EPM were male compared to 74.3\% who were female.

When gender is disaggregated in terms of Employment Sectors, Table 1 had shown that $44.4 \%$ of the respondents were male with Master's Degree in EPM and employed in the public sector as compared to 69.2\% of females that were employed in the public sector. Furthermore, 55.6\% of the respondents were males with a Master's Degree in EPM and employed in the private sector as compared to $30.8 \%$ of females that were employed in the private sector.

Also, when gender is disaggregated in terms of marital status, Table 1 reflected that $22.2 \%$ of the respondents with Master's Degree in EPM were male and single in terms of marital status as compared to $61.5 \%$ of respondents with master's Degree in EPM who were female and single. Similarly, 55.6\% of the respondents with a Master's Degree in EPM were male and married in terms of marital status as compared to $15.4 \%$ of 
respondents with a Master's Degree in EPM who were female and married. Lastly, $11.1 \%$ of the respondents with a Master's Degree in EPM were male and with the marital status that can qualify as complicated as compared to $23.1 \%$ of respondents with Master's Degree in EPM who were female with the marital status that can be considered as complicated.

The average age of male respondents with a Master's Degree was 41.2 years old with a standard deviation of 6.4 while that of female respondents with a Master's Degree was 35.8 years old with a standard deviation of 7.1.

Moreover, the average years of employment of male respondents with a Master's Degree are 8.9 years in service with a standard deviation of 2.5 as compared to female respondents with a Master's Degree is 8.3 years in service with a standard deviation of 3.1.

Lastly, the length of time for a male to finish their Master's Degree is 7 years with a standard deviation of 2.1 as compared to a female which is 7.2 years with a standard deviation of 2.0.

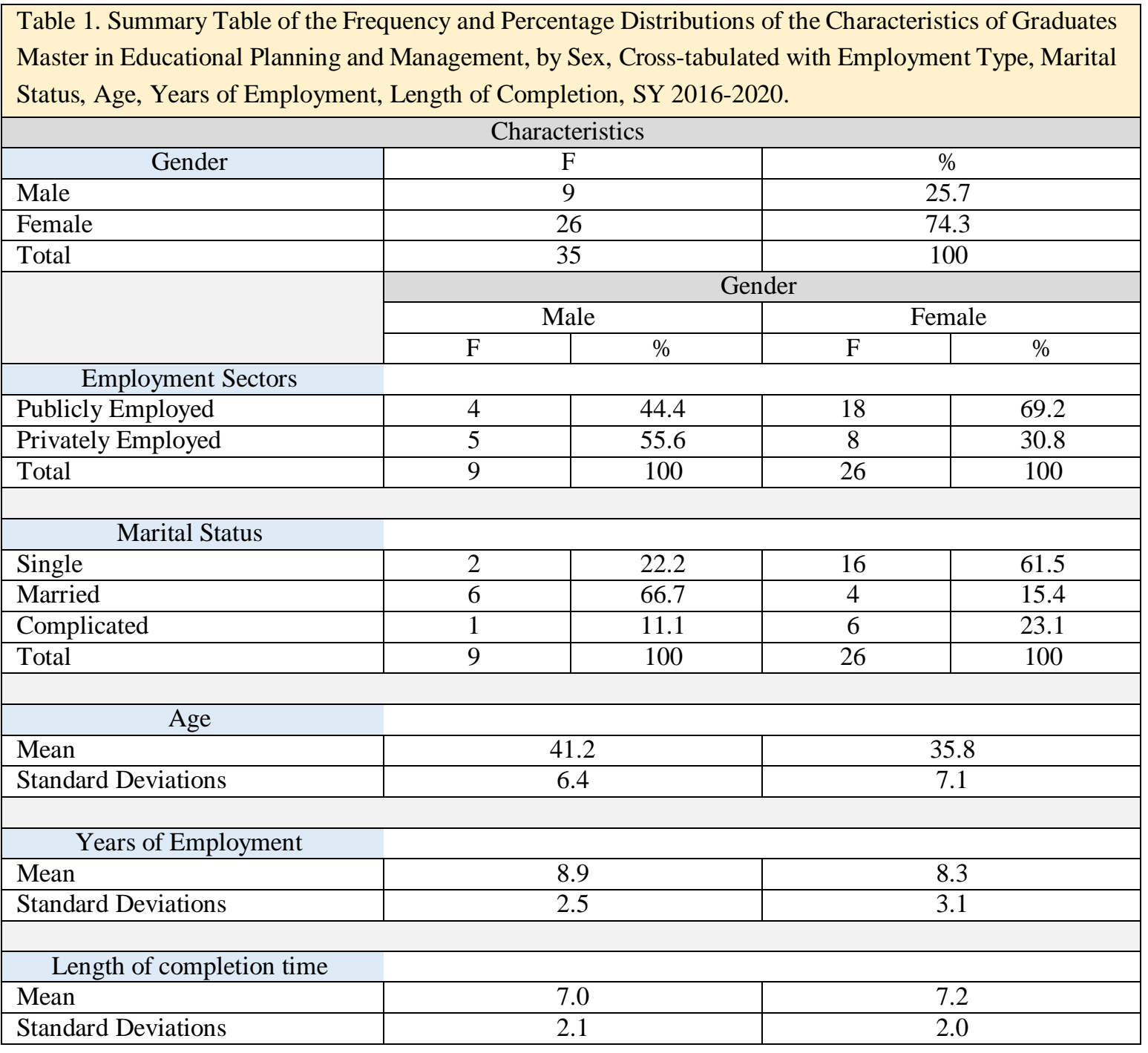


B. Doctorate Student's Respondents Profile with Number of Years of Completion

As reflected in Table 2, 51.5\% of respondents with Doctorate Degree in EPM were male compared to $54.5 \%$ who were female.

When gender is disaggregated in terms of Employment Sectors, Table 2 had shown that $68.8 \%$ of the respondents were male with Doctorate Degree in EPM and employed in the public sector as compared to $70.6 \%$ of females who have such a degree and were employed in the public sector. Furthermore, $31.3 \%$ of the respondents were males with Doctorate Degree in EPM and employed in the private sector as compared to $30.8 \%$ of females who have such a degree and were employed in the private sector.

Also, when gender is disaggregated in terms of marital status, Table 2 reflected that $23.5 \%$ of the respondents with Doctorate Degree in EPM were male and single in terms of marital status as compared to $47.1 \%$ of respondents who have such degree who were female and single. Similarly, $41.2 \%$ of the respondents with Doctorate Degree in EPM were male and married in terms of marital status as compared to $35.3 \%$ of respondents who have such a degree and who were female and married. Lastly, $29.4 \%$ of the respondents with a Doctorate Degree in EPM were male and with the marital status that can be qualified as complicated as compared to $17.6 \%$ of respondents who have such a degree who were female and with the marital status that can be considered as complicated.

The average age of male respondents with Doctorate Degree was 47.1 years old with a standard deviation of 5.4 while that of female respondents who have such a degree was 43.7 years old with a standard deviation of 7.7 .

Moreover, the average years of employment of male respondents with Doctorate Degree are 7.1 years in service with a standard deviation of 3.6 as compared to female respondents who have such a degree is 7.8 years in service with a standard deviation of 2.8 .

Lastly, the length of time for a male to finish their Doctorate Degree is 7.4 years with a standard deviation of 2.5 as compared to a female who has such a degree, which is 6.8 years with a standard deviation of 2.2.

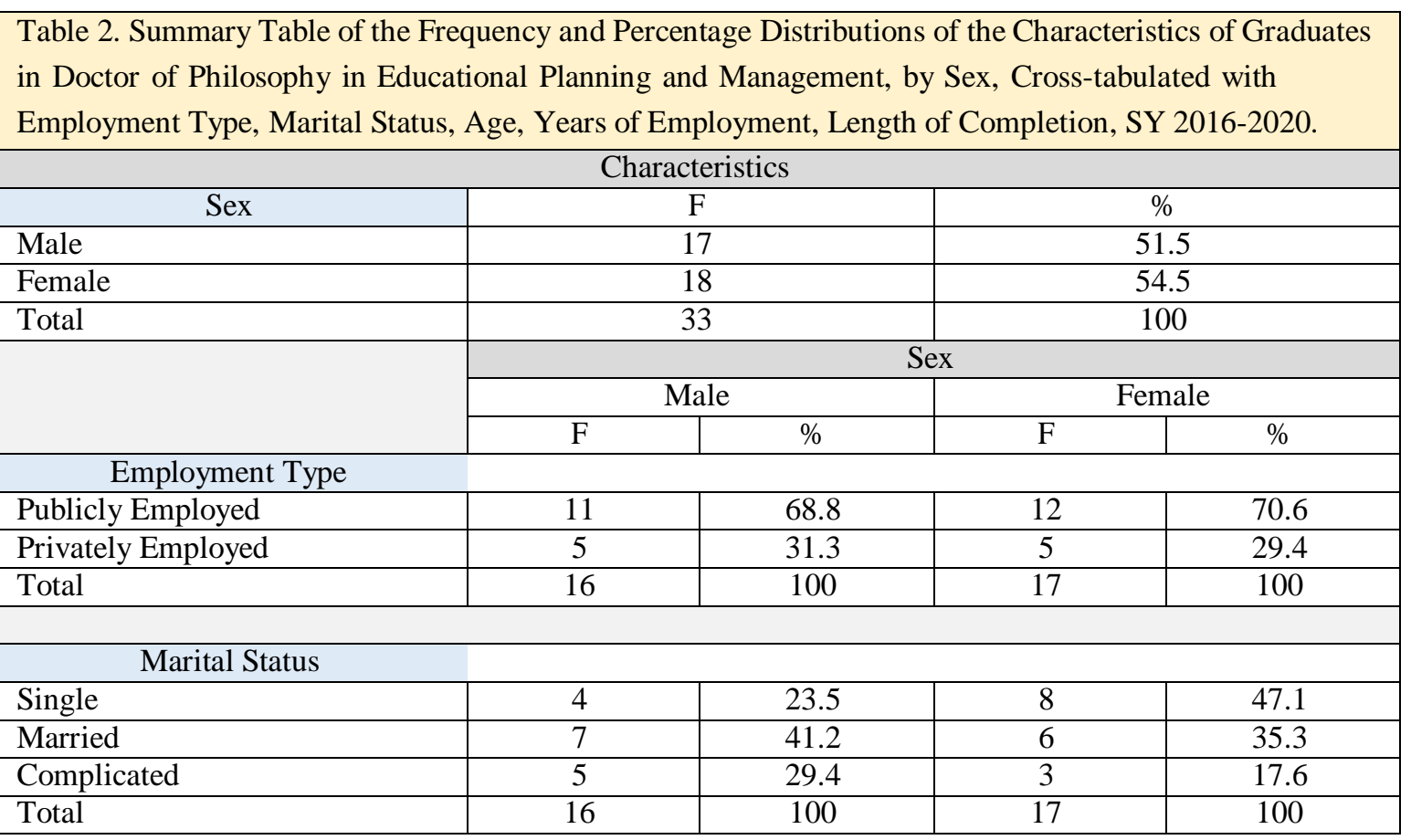




\begin{tabular}{|c|c|c|}
\hline \multicolumn{3}{|l|}{ Age } \\
\hline Mean & 47.1 & 43.7 \\
\hline Standard Deviations & 5.4 & 7.7 \\
\hline \multicolumn{3}{|c|}{ Years of Employment } \\
\hline Mean & 7.1 & 7.8 \\
\hline Standard Deviations & 3.6 & 2.8 \\
\hline \multicolumn{3}{|c|}{ Length of Completion } \\
\hline Mean & 7.4 & 6.8 \\
\hline Standard Deviations & 2.5 & 2.2 \\
\hline
\end{tabular}

B. The Association between Sex and Getting Master and Doctorate Degrees in Educational Planning and Management (EPM)

As shown in Table 3 below, 51.5\% of Ph.D. EPM graduates were males compared to $48.5 \%$ who were females. Furthermore, $25.7 \%$ of Master's EPM graduates were males compared to $74.3 \%$ of females.

The relationship between gender and getting a degree in Educational Planning and Management was tested using the Chi-square test of independence. The result has shown that gender is significantly associated with gender.

Given that the association between gender and the length of time of getting an EPM degree is not attributable to random chance, we proceeded to ascertain its effect size.

Thus, it was shown that the corresponding Phi coefficient is 0.265 , indicative that we have a small effect size. In other words, though gender affects the completion of an EPM degree, be it master's or doctorate, however, the magnitude of such an association is small.

Furthermore, we then look at the probability that students of a given gender can finish an EPM degree. Based on the data shown in Table 3 below, specifically, we attempted to answer the following.

- What is the probability that male students can finish an EPM doctorate?

- What is the probability that female students can finish an EPM doctorate?

- What is the probability that male students can finish an EPM Master's degree?

- What is the probability that female students can finish an EPM Master's degree?

We found out that the probability that male students can finish a Ph.D. Degree in EPM is 65.4\% compared to female, which is $38.1 \%$.

In the same manner, the probability that male students can finish a Master's degree in EPM is $34.6 \%$ compared to females, which is $61.9 \%$.

In summary, though the association of gender with that of EPM degree completion is statistically significant, nonetheless, it appears that a higher number of male students tends to finish a Ph.D. Degree in EPM than that of females. On the other hand, at the master's level, a higher number of female students tend to finish a master's degree in EPM than males.

Table 3. Frequency and Percentage Distributions of Students that Finished Master and Doctorate Degree, by Gender and by Educational Planning and Management Degrees.

\begin{tabular}{|c|c|c|c|c|c|}
\hline \multirow{2}{*}{$\begin{array}{c}\text { Educational Planning and } \\
\text { Management Degrees }\end{array}$} & \multicolumn{3}{|c|}{ Gender } & \multirow{2}{*}{ Totals } \\
\cline { 2 - 5 } & \multicolumn{2}{|c|}{ Male } & \multicolumn{2}{c|}{ Female } & F \\
\cline { 2 - 6 } & F & F & F & $\%$ \\
\hline
\end{tabular}




\begin{tabular}{|c|c|c|c|c|c|}
\hline PhD & $17(.654) *$ & 51.5 & $16(.381)$ & 48.5 & 33 \\
\hline Master & $9(.346)$ & 25.7 & $26(.619)$ & 74.3 & 35 \\
\hline Total & 26 & & 42 & & 68 \\
\hline \multicolumn{7}{|c|}{ Results of Chi-Square Test } \\
\hline
\end{tabular}

A. The Association between Age and Getting Master and Doctorate Degrees in Educational Planning and Management

i. On Getting a Master's Degree in Educational Planning and Administration Relative to Age

The association between age and length of time of getting a Master's Degree in Educational Planning and Management was ascertained.

It was shown to have a correlation coefficient $(\mathrm{R})$ of 0.0382 , that is, a relationship with a positive direction, which could suggest that as age increases the length of time of completing a Master's Degree in Educational Planning and Management would tend to increase. Although the direction of the relationship is positive, nevertheless, the said relationship could be interpreted to mean a very weak one. In the same manner, such relationship was not significant at $\mathrm{p}<.05$, thus, suggestive that the relationship between the two variables, namely, age and length of time of getting a Master's Degree in Educational Planning and Management, could be attributed to random chance rather than a real correlation between the said variables.

As to how much in the length of time in getting a Master's Degree in Educational Planning and Management could be explained by age, the coefficient of determination $\left(R^{2}\right)$ was ascertained. It revealed that only $0.15 \%$ of the variation in the length of time of getting the said degree could be explained by age. In other words, $99.85 \%$ of the variation in the length of time of getting a Master's Degree in Educational Planning and Management could be explained by other factors besides age.

\begin{tabular}{|c|l|r|c|}
\hline \multicolumn{3}{|c|}{ Table 4. Summary Table of the Test of Correlation. } \\
\hline \multirow{4}{*}{ Age } & \multicolumn{1}{|c|}{ Statistics } & $\begin{array}{c}\text { Length of } \\
\text { Completion }\end{array}$ & Remark \\
\cline { 2 - 3 } & Coefficient of Correlation $(\mathrm{R})$ & 0.0382 & \multirow{3}{*}{ Not significant at $\mathrm{p}<.05$} \\
\cline { 2 - 3 } & Coefficient of Determination $\left(\mathrm{R}^{2}\right)$ & 0.0015 & 0.828 \\
\cline { 2 - 3 } & $\mathrm{p}$-value & 35 & \\
\cline { 2 - 3 } & $\mathrm{N}$ & & \\
\hline
\end{tabular}

ii. On Getting a Doctorate Degree in Educational Planning and Administration Relative to Age

The association between age and length of time of getting a Doctorate Degree in Educational Planning and Management was ascertained.

It was shown to have a correlation coefficient $(\mathrm{R})$ of -0.0685 , that is, a relationship with a negative direction, which could suggest that as age increases the length of time of completing a Doctorate Degree in Educational 
Planning and Management would tend to decrease. Although the direction of the relationship is negative, nevertheless, the said relationship could be interpreted to mean a very weak one. In the same manner, such relationship was not significant at $\mathrm{p}<.05$, thus, suggestive that the relationship between the two variables, namely, age and length of time of getting a Doctorate Degree in Educational Planning and Management, could be attributed to random chance rather than a real correlation between the said variables.

As to how much in the length of time in getting a Doctorate Degree in Educational Planning and Management could be explained by age, the coefficient of determination (R2) was ascertained. It revealed that only $0.47 \%$ of the variations in the length of time of getting the said degree could be explained by age. In other words, $99.53 \%$ of the variations in the length of time of getting a Doctorate Degree in Educational Planning and Management could be explained by other factors besides that of age.

Table 5. Summary Table of the Test of Correlation.

\begin{tabular}{|c|l|r|r|}
\hline \multirow{4}{*}{ Age } & \multicolumn{1}{|c|}{ Statistics } & $\begin{array}{c}\text { Length of } \\
\text { Completion }\end{array}$ & Remark \\
\cline { 2 - 3 } & Coefficient of Correlation $(\mathrm{R})$ & -0.0685 & \\
\cline { 2 - 3 } & Coefficient of Determination $\left(\mathrm{R}^{2}\right)$ & 0.0047 & Not significant at $\mathrm{p}<.05$ \\
\cline { 2 - 3 } & $\mathrm{p}$-value & 0.712 & 33 \\
\cline { 2 - 3 } & $\mathrm{N}$ & & \\
\hline
\end{tabular}

B. The Association between Marital Status and Getting Master and Doctorate Degrees in Educational Planning and Management

As shown in Table 6 below, 36.4\% of Ph.D. EPM graduates have a marital status that of single as compared to $39.4 \%$ and $24.2 \%$ whose marital status was that of married and complicated, respectively. Furthermore, $45.7 \%$ of Master's Degree holders in EPM have a marital status that of single as compared to $25.7 \%$ and $28.6 \%$ whose marital status was that of married and complicated, respectively.

The relationship between gender and getting a degree in Educational Planning and Management was tested using the Chi-square test of independence. The result has shown that marital status is not significantly associated with gender. This showed that the association between marital status and the length of time of getting an EPM degree is attributable to random chance nevertheless, we proceeded to ascertain its effect size.

Thus, it was shown that the corresponding Cramer's V is 0.147 , indicative that we have a small effect size. In other words, though marital status did not have a significant association with the length of time in the completion of an EPM degree, be it master's or doctorate, however, the magnitude of such an association is small.

Furthermore, we then look at the probability that students with a given marital status can finish an EPM degree. Based on the data shown in Table 6 below, specifically, we attempted to answer the following.

- What is the probability that students with the marital status of single can finish an EPM doctorate?

- What is the probability that students with the marital status of married can finish an EPM doctorate?

- What is the probability that students with the marital status of complicated can finish an EPM doctorate?

- What is the probability that students with the marital status of single can finish an EPM master's degree?

- What is the probability that students with the marital status of married can finish an EPM master's degree?

- What is the probability that students with the marital status of complicated can finish an EPM master's degree? 
We found out that the probability that students with the marital status of a single can finish a Ph.D. Degree in EPM is $42.9 \%$ compared to $59.1 \%$ and $44.4 \%$ whose marital status is married and complicated, respectively.

In the same manner, the probability that students with the marital status of a single can finish a Master's Degree in EPM is $51.7 \%$ compared to $40.9 \%$ and $55.6 \%$ whose marital status is married and complicated, respectively.

In summary, though the association of marital status with that of EPM degree completion is not statistically significant, nonetheless, it appears that a higher number of students with a marital status of married tends to finish a Ph.D. Degree in EPM vis-à-vis single and complicated marital status. On the other hand, at the master's level, a higher number of students with a marital status of single tends to finish a master's degree in EPM visà-vis married and complicated marital status.

\begin{tabular}{|c|c|c|c|c|c|c|c|}
\hline \multirow{3}{*}{$\begin{array}{c}\text { Educational } \\
\text { Planning and } \\
\text { Management } \\
\text { Degrees }\end{array}$} & \multicolumn{6}{|c|}{ Marital Status } & \multirow{3}{*}{$\begin{array}{r}\text { Totals } \\
(\mathrm{N}=68)\end{array}$} \\
\hline & \multicolumn{2}{|c|}{ Single } & \multicolumn{2}{|c|}{ Married } & \multicolumn{2}{|c|}{ Complicated } & \\
\hline & $\mathrm{F}$ & $\%$ & $\mathrm{~F}$ & $\%$ & $\mathrm{~F}$ & $\%$ & \\
\hline $\mathrm{PhD}$ & $12(.429)$ & 36.4 & $13(.591)$ & 39.4 & $8(.444)$ & 24.2 & 33 \\
\hline Master & $16(.571)$ & 45.7 & $9(.409)$ & 25.7 & $10(.556)$ & 28.6 & 35 \\
\hline total & 28 & & 22 & & 18 & & 68 \\
\hline \multicolumn{8}{|c|}{ Results of Chi-Square Test } \\
\hline \multicolumn{8}{|c|}{ The chi-square statistic is 1.4634 . The p-value is .481099 . The result is not significant at $\mathrm{p}<.05$. } \\
\hline \multicolumn{8}{|c|}{$\begin{array}{l}\text { Based on the information provided, it is found that the Chi-Square statistic is } 1.4634 \text {, and the } \\
\text { corresponding Cramer's V is } 0.147 \text {, which indicates that we have a small effect size. }\end{array}$} \\
\hline \multicolumn{8}{|c|}{$\begin{array}{l}\mathrm{H}_{0} \text { : There is no significant association between marital status and the completion of an EPM degree. } \\
\mathrm{H}_{1} \text { : There is a significant association between marital status and the completion of an EPM degree. }\end{array}$} \\
\hline \multicolumn{8}{|c|}{$\begin{array}{l}\text { Interpretation: Accept null hypothesis. There is no significant association between marital status and the } \\
\text { length of time in completing an EPM degree. }\end{array}$} \\
\hline
\end{tabular}

C. The Association between Years in Employment and Getting Master and Doctorate Degrees in Educational Planning and Management

i. On Getting a Master's Degree in Educational Planning and Administration Relative to Years of Employment

The association between years of employment and length of time of getting a Master's Degree in Educational Planning and Management was ascertained as depicted in Table 8 below.

It was shown to have a correlation coefficient $(\mathrm{R})$ of -0.2905 , that is, a relationship with a negative direction, which could suggest that as years of employment increases the length of time of completing a Master's Degree in Educational Planning and Management would tend to decrease. Although the direction of the relationship is negative, nevertheless, the said relationship could be interpreted to mean a very weak one. In the same manner, such relationship was not significant at $\mathrm{p}<.05$, thus, suggestive that the relationship between the two variables, namely, years of employment and length of time of getting a Master's Degree in Educational Planning and Management, could be attributed to random chance rather than a real correlation between the said variables.

As to how much in the length of time in getting a Master's Degree in Educational Planning and Management could be explained by years of employment, the coefficient of determination $\left(\mathrm{R}^{2}\right)$ was ascertained. It revealed that only $0.084 \%$ 
of the variations in the length of time of getting the said degree could be explained by years of employment. In other words, $99.92 \%$ of the variations in the length of time of getting a Master's Degree in Educational Planning and Management could be explained by other factors besides that of years of employment.

\begin{tabular}{|c|c|c|c|}
\hline & & $\begin{array}{c}\text { Length of } \\
\text { Completion }\end{array}$ & Remark \\
\hline \multirow{3}{*}{$\begin{array}{c}\text { Years of } \\
\text { Employment }\end{array}$} & Coefficient of Correlation (R) & -0.2905 & \multirow{3}{*}{ Not significant at $\mathrm{p}<.05$} \\
\hline & Coefficient of Determination $\left(\mathrm{R}^{2}\right)$ & 0.0844 & \\
\hline & p-value & .091 & \\
\hline
\end{tabular}

ii. On Getting a Doctorate Degree in Educational Planning and Administration Relative to Years of Employment

The association between years of employment and length of time of getting a Doctorate Degree in Educational Planning and Management was ascertained as depicted in Table 8 below.

It was shown to have a correlation coefficient $(R)$ of -0.0475 , that is, a relationship with a negative direction, which could suggest that as years of employment increases the length of time of completing a Doctorate Degree in Educational Planning and Management would tend to decrease. Although the direction of the relationship is negative, nevertheless, the said relationship could be interpreted to mean a very weak one. In the same manner, such relationship was not significant at $p<.05$, thus, suggestive that the relationship between the two variables, namely, years of employment and length of time of getting a Doctorate Degree in Educational Planning and Management, could be attributed to random chance rather than a real correlation between the said variables.

As to how much in the length of time in getting a Doctorate Degree in Educational Planning and Management could be explained by years of employment, the coefficient of determination $\left(\mathrm{R}^{2}\right)$ was ascertained. It revealed that only $0.002 \%$ of the variations in the length of time of getting the said degree could be explained by years of employment. In other words, $99.98 \%$ of the variations in the length of time of getting a Doctorate Degree in Educational Planning and Management could be explained by other factors besides that of years of employment.

\begin{tabular}{|c|l|r|r|}
\hline \multicolumn{2}{|c|}{ Table 8. Summary Table of the Test of Correlation. } \\
\hline \multicolumn{2}{|c|}{} & $\begin{array}{c}\text { Length of } \\
\text { Completion }\end{array}$ & \multicolumn{1}{c|}{ Remark } \\
\hline \multirow{2}{*}{$\begin{array}{c}\text { Years of } \\
\text { Employment }\end{array}$} & Coefficient of Correlation $(\mathrm{R})$ & -0.0475 & \multirow{2}{*}{ Not significant at $\mathrm{p}<.05$} \\
\cline { 2 - 3 } & Coefficient of Determination $\left(\mathrm{R}^{2}\right)$ & 0.0023 & .825 \\
\cline { 2 - 3 } & p-value & \\
\hline
\end{tabular}

D. The Association between Employment Sector and Getting Master and Doctorate Degrees in Educational Planning and Management.

As shown in Table 9 below, $30.3 \%$ of Ph.D. EPM graduates were employed in the private sector as compared to $69.7 \%$ of those connected in the public sector. Furthermore, 37.1\% of Master's Degree holders in EPM were employed in the private sector as compared to $62.9 \%$ of those employed in the public sector.

The relationship between employment and the number of graduates getting degrees in Educational Planning and 
Management was tested using the Chi-square test of independence. The result has shown that the employment sector is not significantly associated with the number of graduates getting degrees in EPM. This showed that the association between marital status and the number of graduates getting degrees in EPM is attributable to random chance, nevertheless, we still proceeded to ascertain its effect size.

Thus, it was shown that the corresponding Cramer's V is 0.072 , indicative that we have a small effect size. In other words, though marital status did not have a significant association with the length of time in the completion of an EPM degree, be it master's or doctorate, however, the magnitude of such an association is small.

Furthermore, based on the data shown in Table 6 below, we then look at the probability of students with a given employment sector can finish an EPM degree. Specifically, we attempted to answer the following.

- What is the probability that students who were publicly employed can finish an EPM doctorate?

- What is the probability that students who were privately employed can finish an EPM doctorate?

- What is the probability that students who were publicly employed can finish an EPM master's degree?

- What is the probability that students who were privately employed can finish an EPM master's degree?

We found out that the probability that students who are privately employed can finish a Ph.D. Degree in EPM is $43.5 \%$ compared to $51.1 \%$ when employed in the public sector.

In the same manner, the probability that students who are privately employed can finish a Master's Degree in EPM is $56.5 \%$ compared to $48.9 \%$ when employed in the public sector.

In summary, though the association of the employment sector with the numbers of graduates getting EPM degrees is not statistically significant, nonetheless, it appears that a higher number of students from the public sector tends to finish a Ph.D. Degree in EPM vis-à-vis those in the private sector. On the other hand, at the master's level, a higher number of students employed in the private sector tend to finish a master's degree in EPM vis-à-vis those in the public sector.

Table 9. Frequency and Percentage Distributions of Master and Doctorate Students, by Marital Status and by Educational Planning and Management Degrees.

\begin{tabular}{|c|c|c|c|c|c|}
\hline \multirow{3}{*}{$\begin{array}{l}\text { Educational } \\
\text { Planning and } \\
\text { Management } \\
\text { Degrees }\end{array}$} & \multicolumn{4}{|c|}{ Employment Sector } & \multirow{3}{*}{$\begin{array}{c}\text { Totals } \\
(\mathrm{N}=68)\end{array}$} \\
\hline & \multicolumn{2}{|c|}{ Private } & \multicolumn{2}{|c|}{ Public } & \\
\hline & $\mathrm{F}$ & $\%$ & $\mathrm{~F}$ & $\%$ & \\
\hline $\mathrm{PhD}$ & $10(.435)$ & 30.3 & $23(.511)$ & 69.7 & 33 \\
\hline Master & $13(.565)$ & 37.1 & $22(.489)$ & 62.9 & 35 \\
\hline Total & 23 & & 45 & & 68 \\
\hline \multicolumn{6}{|c|}{ Results of Chi-Square Test } \\
\hline \multicolumn{6}{|c|}{ The chi-square statistic is 0.355 . The $\mathrm{p}$-value is .551219 . The result is not significant at $\mathrm{p}<.05$. } \\
\hline \multicolumn{6}{|c|}{$\begin{array}{l}\text { Based on the information provided, it is found that the Chi-Square statistic is } 1.4634 \text {, and the } \\
\text { corresponding Cramer's V is } 0.072 \text {, which indicates that we have a small effect size. }\end{array}$} \\
\hline \multicolumn{6}{|c|}{$\begin{array}{l}\mathrm{H}_{0} \text { : There is no significant association between the employment sector and the completion of an EPM } \\
\text { degree. } \\
\mathrm{H}_{1} \text { : There is a significant association between the employment sector and the completion of an EPM } \\
\text { degree. }\end{array}$} \\
\hline
\end{tabular}




\section{Conclusion}

Given the overall objective of the study, we, therefore, arrived at the conclusion that of the characteristics being considered in this study for its association with getting a master or doctorate in Educational Planning and Management only Gender was found to be significantly associated with the completion of master and doctorate in Educational Planning and Management. In other words, there is indeed a real-world association of Gender in the completion of a master's or doctorate in Educational Planning and Management, and such could not be attributed to random chance.

The rest of the characteristics being considered in this study, namely, age, marital status, and employment sector though associated with getting a master's or doctorate, is more attributable to random chance rather than the existence of association in the real world.

\section{Recommendations}

Based on the above conclusion, there is a need for the Department to widen the coverage of the characteristics of students that should be included in their profile. As much as possible it should include socio-cultural and economic indicators and psycho-emotional and intellectual considerations as well. In this way, the next profile of the entrants for the new curriculum, which is aptly named educational planning and administration will be more comprehensive and encompassing as compared to the previous one. The more characteristics or indicators will be incorporated in the profiling of students, the more it becomes a valuable source of data for future study.

\section{References}

Abedi, J., \& Benkin, E. (1987). The effects of students' academic, financial, and demographic variables on time to the doctorate. Research in Higher Education, 27, 3-14.

Baird, L.L. (1990). Disciplines and doctorates: The relationships between program characteristics and the duration of doctoral study. Research in Higher Education, 31, 369-385.

Berelson, B. (1960). Graduate education in the United States. New York: McGraw-Hill. Berg, H.M., \& Ferber, M.A. (1983). Men and women graduate students: Who succeeds and why? Journal of Higher Education, 54, 629648.

Berg and Ferber (1983) Men and Women Graduate Students: Who Succeeds and Why? The Journal of Higher Education, 54:6, 629-648, DOI: 10.1080/00221546.1983.11780187

Bowen, W.G., \& Rudenstine, N.L. (1992). 1n pursuit of the Ph.D. Princeton, N.J.: Princeton University Press.

Duggan, J J. (1989). Time to the doctoral degree and success rates: The Berkeley experience. Unpublished data, University of California at Berkeley.

Evangelauf, J. (1989, March 15). Lengthening of time to earn a doctorate causes concern. Chronicle of Higher Education, 13-14.

Filteau, C. (Ed.). (1992). Graduate graduation rates and time-to-completion: Colloquium proceedings. Toronto, Ontario, Canada: Ontario Council on Graduate Studies.

Fletcher, J., \& Stren, R. (1992). Discussion of the factors influencing time-to-completion in graduate programs: Student views. In C. Filteau (Ed.), Graduate graduation rates and time-to-completion: Colloquium

proceedings. Toronto, Ontario, Canada: Ontario Council on Graduate Studies.

MacMillan, B. (1989). The flow-through hypothesis: A review of the data. In C. Filteau (Ed.), Proceedings of a conference of women in graduate studies in Ontario. Toronto, Ontario, Canada: Ontario Council on Graduate Studies.

Marr, W., \& McPherson, B. (1992). Graduation rates and time-to-completion in master's-only programs. In C. Filteau (Ed.), Graduate graduation rates and time-to-completion: Colloquium proceedings. Toronto, Ontario, Canada: Ontario Council on Graduate Studies.

National Research Council. (1989). Summary Report 1987: Doctoral recipients from United States 
universities. Washington, D.C.: Author.

Ott, M.D., Markewich, T.S., \& Ochsner, N.L. (1984). Logit analysis of graduate student retention. Research in Higher Education, 21,439-460.

Pyke, S.W., \& Sheridan, P.M. (1993). Logistic regression analysis of graduate student retention. Canadian Journal of Higher Education, 23,44-64.

Sheinin, R. (1989). Review of the implementations of the recommendations of the Report on the "Status of Women in Ontario Universities." In C. Filteau (Ed.), Proceedings of a conference of women in graduate studies in Ontario. Toronto, Ontario, Canada: Ontario Council on Graduate Studies.

Sheridan, P.M. (1992). Factors influencing graduation rates and time-to-completion in master's programs at York University. In C. Filteau (Ed.), Graduate graduation rates and time-to-completion: Colloquium proceedings. Toronto, Ontario, Canada: Ontario Council on Graduate Studies.

Tuckman, H.P., Coyle, S., \& Bae, Y. (1990). On-time to the doctorate. Washington, DC: National Academy Press.

Yeates, M. (1991). Doctoral graduation rates in Ontario universities. Toronto, Ontario, Canada: Council of Ontario Universities/Ontario Council on Graduate Studies. 